\title{
Non-compliance and its associated factors among hypertensive patients taking anti-hypertensive treatment visiting Gimbi general hospital,Western Ethiopia:cross-sectional study
}

Firomsa Bekele ( $\sim$ firomsabekele21@gmail.com )

Mettu university

Ginenus Fekadu

wollega university

Dinka Dugassa

Nekemte referral hospital

Kumera Bekele

Selale university

Research note

Keywords: Hypertension, Hypertensive treatment, Adherence, Compliance

Posted Date: January 21st, 2020

DOI: https://doi.org/10.21203/rs.2.10283/v2

License: (c) (1) This work is licensed under a Creative Commons Attribution 4.0 International License.

Read Full License 
The authors have withdrawn this preprint from Research Square 